\title{
THE COMMERCIALISATION OF KNOWLEDGE MANAGEMENT PRACTICES TO K-BASED DEVELOPMENT IN MALAYSIA
}

\author{
Raja Suzana Raja Kasim \\ Universiti Teknologi MARA, Shah Alam, Selangor, Malaysia \\ rsuzana@salam.uitm.edu.my
}

\begin{abstract}
This paper studies the connection between the commercialisation of knowledge management practices and its contributions toward the knowledge-based development in Malaysia. Theoretical relations in this paper were tested through an empirical study carried out among public-listed organisations in the industrial products, consumer products, and service industries in Malaysia. The findings of this paper revealed that it is important for corporations to focus on knowledge management in the development of the organisation's corporate strategy. Empirical evidence supported the view that firms with knowledge management capabilities and understanding will utilise these capabilities to drive their quality strategy, thus performing better than those that do not. In addition, the finding serves as an initial move among private sector business toward a knowledge-based country. This paper concludes that these practices have a positive incidence not only on the performance of the firm but it also gives some initial contributions toward the development of Malaysia as a knowledge-based country.
\end{abstract}

Keywords: Knowledge-based development, Corporate strategies, Firm performance, Public-listed organisations, Malaysia.

\section{INTRODUCTION}

The $21^{\text {st }}$ century's knowledge economy is marked by major developing trends such as pervasive computing, mass customisation, continuous learning, globalised competition, collaborative partnering and virtual enterprises. It is an economy in which value flows from the technology and practices used to harness an organisation's knowledge resources and knowledge-processing skills. In order to remain competitive, initiatives to expand the market for 
Malaysian products and services has to be undertaken by strengthening the country's position in traditional markets and by exploring new markets. As such, initiatives to liberalise trade under World Trade Organisations (WTO), AFTA, as well as bilateral free trade arrangements with countries in East Asia, South Asia, and Asia Pacific, are expected to expand Malaysia's global reach. One of the biggest challenges under the Ninth Malaysia Plan is managing knowledge in human capital and its related development, and upgrading the mental capabilities and intellectual capacity of a nation. The move toward globalisation means that the country is embracing knowledge-based economy, where the development of human capital is a high priority. In order to remain competitive, private organisations in Malaysia have to utilise their strategic resources more proactively and make their objectives and practices consistent with the organisation's vision and policy.

In light of these developments, organisations through their corporate management and those involved in the developing strategies should take note of the major impact of knowledge in the formulation of corporate strategy (CS) and its ultimate goals. Initially, there would be a need to look at outcomes derived from an analysis of the internal organisation to better position the company to prevail in the ongoing competitive challenges it confronts. The alignment of knowledge management (KM) strategy and CS directs an organisation to maintain its long-term position and sustain the firm's competitive advantage. Subsequesntly, this study explored the scope of the knowledge activities among firms and the extent to which these practices contribute to the performance of the organisation in a way it could contribute toward the initial development of the knowledge-based movement in Malaysia.

\section{STATEMENT OF PROBLEM}

Research which integrates knowledge management practices (KMP), CS, and its impact on firm performance (FP) as a contributing factor toward the initial development of knowledge-based activities among industries in Malaysia is still scant. Although many studies have been conducted, they were carried out in isolation. Furthermore, whether organisations are able to leverage on the optimum use of their strategic resources through appropriate KMP and integrating these practices into every aspect of CS in order to improve organisational performance, and how it contributes toward knowledge-based development in Malaysia appears to have received little attention.

This study addressed the question of whether a combination of the successful type of both CS and KMP exists that is predictive of FP in the forms of both financial and non-financial outcome among public-listed organisations in 
Malaysia. The public-listed organisations have been selected due to their high engagement in the knowledge-based activities particularly those in the consumer products, industrial products, and services industries. As such, investigation of alternative and interactive models can contribute to strategic management theory and knowledge-based view of the firm theory by providing additional insights in the relationships between the KM and FP model. In order to advance the theory, it is necessary to develop alternative hypotheses that investigate the interaction effects. The fit between KMP and corporate strategy as strategic elements may have a positive impact on FP and contribute toward knowledge-based development in the country.

\section{FIRM PERFORMANCE}

Firm Performance this study reviewed both the strategic management research and knowledge management stream to discover the underlying constructs that frame FP. A number of studies in the strategic management field advocated the different intra-firm deals with both elements of organisational and environmental variables. Such differences reflect characteristics and indicators that most firms have to deal with, particularly in planning, executing, and implementing CS (Schendel, 1996; McGivern Tvorik, 2005). This is further supported by many studies when incorporating Miles and Snow typology (1978) which is later extended by Conant, Mokwa and Varadarajan (1990) in differentiating the organisation's actions toward various strategy and the success, depend on whether the firm is categorised under prospector, analyser, defender or reactor category (Norziha, 2005; Rozhan, Rahayu \& Rashidah, 2001; Zabid \& Anantharaman, 1997; Raja Hanaliza, 2005; Raja Suzana, 2005). Hence, this generally accounts for differences in terms of developing the organisation's own CS and its impact toward FP. In turn, the strategy differential will result in low, normal, or supernormal performance consequences (Hambrick, 1983).

Corporate Strategies-in the context of this study and based on the literature, the researchers combined some earlier proponents of strategy such as Miles and Snow (1978), Robbins (1990), and Chandler (1962), and defined CS as achieving the fit between the organisational strategic resources, structures, and processes. The corporate strategic choice resolves around the internal and external issues and behaviour of the organisation, and technological and administrative problems of the firm.

The resource-based view of the firm-developed in various work by Wernerfelt (1984), Barney (1996), Teece (2000), Teece, Pisano, and Shuen (1999), Prahalad and Hamel (1990), Penrose (1959), and Chandler (1962)the resource-based view asserted that a business enterprise is best viewed 
as a collection of sticky and difficult-to-imitate resources and capabilities (Penrose, 1959; Wernerfelt, 1984; Barney, 1996.

The knowledge-based view of the firm-Kogut and Zander (1996) define the meaning of organising knowledge in the organisation as the main motive the knowledge-based view of the firm exists. These authors define the meaning of organising knowledge as viewed by knowledge-based view theorists as a social community specializing in the speed and efficiency of the creation and transfer of knowledge.

Knowledge Management Practices-in fact, there is no single ultimate definition of knowledge management (Darroch, 2003; McCann \& Buckner, 2004; Diakoulakis, Georgopulos, Koulouriotis \& Emiris, 2004; LengnickHall \& Lengnick-Hall, 2003, p. 85). However, knowledge management has been regarded as an interdisciplinary field that draws on a variety of business activities and academic specialisations. In an attempt to accelerate the efficiency and effectiveness of managing knowledge issues and in the context of this study, there is a need to align them with relevant KMP and strategic choices of the firm. Hence, in achieving a fit between the elements of CS and KMP, the researchers defined KM as activities which are concerned with systematic, effective management and utilisation of an organisation's knowledge resources where it encompasses the acquisition, dissemination, and responding to an organisation's knowledge which provides effective and efficient value-chain within the strategic and functional needs of the organisation. Consequently, in solving various processes, problems, and challenges encountered by organisations, two major themes are apparent, namely (i) knowledge value chain and (ii) KMP goal.

The underlying principle of this theoretical model, as in Figure 1, is the need to build into organisations the attributes that create conditions which allow employees and managers who are involved in knowledge issues to assume more responsibility and accountability for planning, organising, controlling, and executing their tasks in solving issues. On the strength that the theoretical model and conceptual basis can be used to assess each intended element of CS and KMP that can create opportunities for meaningful and challenging work, hence, both the CS and KMP dimensions of the model serve as the conceptual framework of this study. 


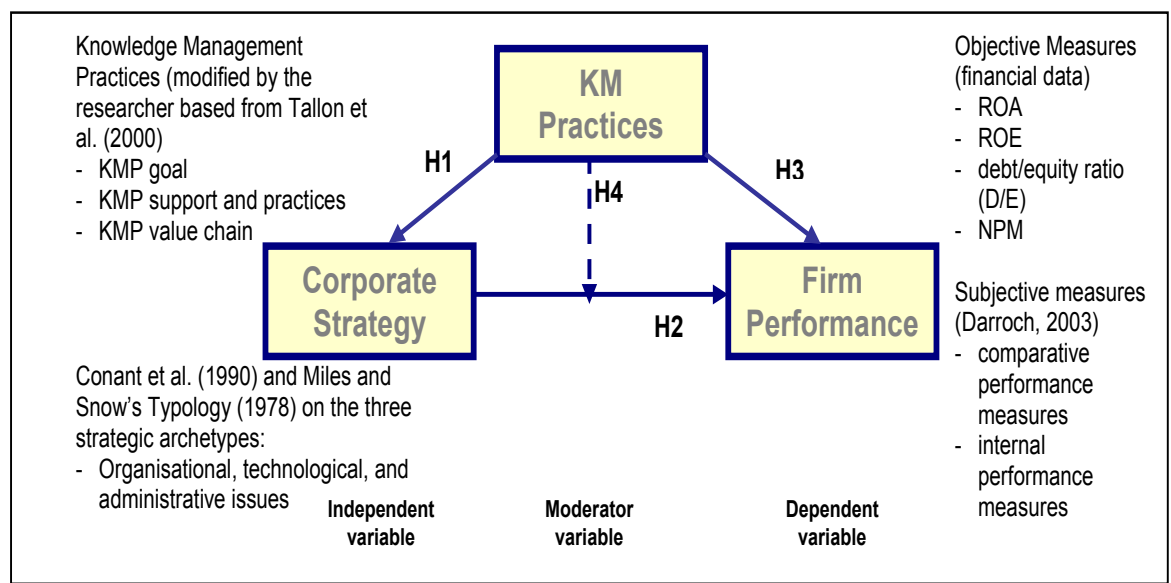

\section{Fig. 1: Theoretical Model}

Hypotheses-the conceptual framework as illustrated in Figure 1, has three key major components: CS, KMP and FP. CS serves as the independent variable of this study, while KMP, the moderating variable. FP is the dependent variable. The following hypotheses were formulated based on the research evidence found particularly from the descriptive studies of the relationship between CS, KMP, and FP.

Snyman and Kruger (2004) in their study found that a fit between the organisation's strategy and its knowledge management strategy can be achieved by exploiting organisational strategic resources and its corporate intent. The CS appears to be successful when the knowledge strategy and knowledge program is consistent with corporate ambitions and that the techniques, technologies, resources, roles, and skills, are aligned and support the business objectives. Hence, the researchers derived the following hypothesis; $\mathrm{H}_{0} 1$ : there is a significant relationship between each of the KMP and CS pursued.

That Raja Suzana (2004) and Raja Suzana (2005) stressed the key issue in strategy is to have a unique offering (low cost, high quality) in aspects of the organisational products or services. Hence, in this turbulent environment, resources appear to be useful particularly in transforming relevant knowledge to useful products and services. These resources are then used in activities which are needed in order to produce a service or product, to be supplied to customers. Based on the evidence, the linkage was anticipated as follows: $\mathrm{H}_{0}$ 2: there is a significant relationship between each of the CS pursued and FP.

Parnell, Lester and Menefee (2000) sought the responses from 137 wholesale grocers in their effort to find out an alternative perspective on the knowledge 
strategy-performance relationship. They followed Conant et al. (1990) who had developed the item scale in the original of Miles and Snow's (1978) typology. While for the FP, the return on asset (ROA) for three years was examined. The result of this study demonstrated that uncertainty varies by generic strategy, suggesting that businesses consider both the type and degree of uncertainty when crafting a competitive strategy that leads to superior FP. Hence, the researchers derived the following hypotheses; $\mathrm{H}_{0} 3$ : there is a significant relationship between each KMP and FP.

In an attempt to seek the moderating effects of KMP on the relationship of CS and FP, many studies had been conducted in isolation and they did not specifically determine and explore the moderating factor of KMP. Hence, this study contributes to a new area in the Malaysian context since no previous research was undertaken. The linkage is anticipated as follows; $\mathrm{H}_{0} 4$ : there is a positive relationship between CS and FP, moderated by KMP.

\section{RESEARCH METHODOLOGY}

In order to test the research model, the researchers conducted a cross-sectional survey among public-listed organisations in Malaysia. A self-administered questionnaire was designed and delivered to 325 organisations. This study addresses the question of whether a combination of the successful type of both CS and KMP exists that is predictive of FP in the forms of both financial and non-financial outcome among public-listed organisations in Malaysia. The public-listed organisations were selected due to their high engagement in knowledge-based activities.

A total of 325 questionnaires were mailed to 325 public-listed organisations in Malaysia. From this, 155 organisations responded to the survey, representing a $48 \%$ response rate. However, 32 responses were unusable ( 9 due to incomplete answers, 11 were returned blank, and another 12 refused to participate mostly due to company policy). Hence, a total of 123 responses were received and the effective response rate was $38 \%$. These response rates are comparable to similar previous studies involving top executives. For example, Asoh (2004) surveyed top executives of firms in a study of the alignment of strategy and knowledge strategy. The author reported a response rate of 13\%. Considering that mail surveys generally have low response rate, this level of response is satisfactory (Sekaran, 2000) and exceeds the calculated sample size of 120, using the G-Power analysis of a medium effect size of .15 (Cohen \& Cohen, 1977). 
The instrument was categorised into four sections and the alpha coefficient was calculated for the four sections and for the questionnaire in its entirety. The level of significance for items was established at .05. The Alpha score obtained for all the four sections were above .89 , that which was well above the .70 level and this was generally acceptable for field research (Hair, Anderson, Tatham, \& Black 1998). Additionally, according to Sekaran (2000), the value of alpha level of more than 0.6 shows the research instrument to be reliable for the purpose of the study. This result therefore, suggested that the questionnaire is a reliable instrument to consistently measure the level of knowledge practices and the CS pursued in these organisations. All the question items were measured on the 10 point Likert scale from "don't agree at all" (1) to "completely agree" (10).

\section{RESULTS}

Moderated Multiple Regressions (MMR) using higher-order interaction analysis was conducted. MMR is an inferential procedure which consists of comparing two different least-square regression equations (Aguinis, 2004). The researchers chose MMR as it allows researchers to analyse both how well the measures relate to each construct and how the independent variables influence the dependent variable. In addition, the Pearson Product moment correlation coefficient was also conducted to test the relationship between two variables. The Cronbach Alpha test was used to test the reliability of the research instrument. All the reliability coefficients (Cronbach Alpha) were above 0.6 , and within the acceptable range (Nunally, 1978). All the dimensions of the Cronbach Alpha exceeded 0.7.

Assessment of the Model-Two models were tested to assess the effects of a moderating variable. Model 1 excluded the interaction effects and Model 2 included all the interaction effects as shown in Table IV. In formulating and testing interaction effect, the research applied a procedure described by Aguinis (2004). The value of the $\mathrm{R}^{2}$ for Model 1 and $\mathrm{R}^{2}$ for Model 2 were compared to assess the moderating strength of KMP in total. In addition, the result of the R-square Coefficient is also presented in Table 1 to determine the relationship between each independent variable and dependent variable. All three hypotheses were supported and have a significant association between each variable at the 0.001 level. 
Table 1: The Result of the R-square Coefficient

\begin{tabular}{ccc}
\hline Hypothesis Tested & R- Coefficient & R - square Coefficient \\
\hline H1 & $0.64^{* *}$ & 0.41 \\
H2 & $0.50^{* *}$ & 0.25 \\
H3 & $0.50^{* *}$ & 0.23 \\
\hline
\end{tabular}

As shown in Table 1, all R-Coefficients regarding the positive association $(\mathrm{H} 1, \mathrm{H} 2$ and $\mathrm{H} 3)$ were significant at the 0.001 level and the path coefficients regarding direct effect for $\mathrm{H} 4$ was also significant at the 0.001 level. For Model 1, as in Table 2, the explained variance $\mathrm{R}^{2}$ was .490 , indicating that the CS explained $49 \%$ variance. With the introduction of KMP [product term - $\left.\left(\mathrm{b}_{3} \mathrm{CS} . \mathrm{KMP}_{1}+\mathrm{b}_{4} \mathrm{CS} . \mathrm{KMP}_{2}+\mathrm{b}_{5} \mathrm{CS} . \mathrm{KMP}_{3}\right)\right]$ in Model 2, $\mathrm{R}^{2}$ was increased to .621. The addition of the product term resulted in an $\mathrm{R}^{2}$ change of .131, $\mathrm{F}$ (3, $117)=13.487 \mathrm{p}<0.001$. These results supported the presence of a moderating effect. In other words, the moderating effect of KMP explains $13.1 \%$ of variance in FP increase and beyond the variance explained by CS scores and KMP choices.

Table 2: The Result of the MMR

\begin{tabular}{lcrrr} 
& \multicolumn{2}{c}{ Model 1 } & \multicolumn{2}{c}{ Model 2 } \\
\cline { 2 - 5 } Hypothesis Tested & \multicolumn{1}{c}{ Beta } & T-value & Beta & T-value \\
\hline H4- CS*KMP & & & & \\
CS & $.139^{\text {ns }}$ & 1.759 & $.266^{* *}$ & 2.904 \\
KMP & $.612^{* *}$ & 7.757 & $1.990^{* *}$ & 2.374 \\
CS.KMP & & & $1.062^{* *}$ & -2.487 \\
$\mathrm{R}^{2}$ & .490 & & .621 & \\
Adjusted $\mathrm{R}^{2}$ & .482 & & .605 & \\
\hline Notes: ${ }^{* *} \mathrm{p}<0.001,{ }^{\mathrm{ns}}$ non-significant & &
\end{tabular}

The higher-order interaction effects of the MMR test was conducted to differentiate the level of those who adopted KMP and non-KMP. The Coefficients Table as shown above also includes information regarding the regression coefficients after the product term is entered in the equation. The equation is the following:

Equation 1:

$$
\begin{aligned}
& \mathrm{FP}=-.1 .218+.323 \mathrm{CS}+1.726 \mathrm{KMP}-.272 \mathrm{CSXKMP}_{1}+ \\
& .126 \mathrm{CSXKMP}_{2}+.341 \mathrm{CSXKMP}
\end{aligned}
$$


The CS - FP relationship for each group is shown in Figure 2 below. The researchers chose values of 1 (SD) above and below the mean for CS (Cohen \& Cohen , 1977; Aguinis, 2004). Referring to the mean score for CS being and the standard deviation (SD) being 69 from the descriptive results, the value of $1 \mathrm{SD}$ above and below the mean was created. Hence, using the value of 6.70 (1 SD above the mean) and 4.89 (1 SD below the mean), yielded the graph shown in Figure 2. Results from Equation 1 led to the conclusion that there is a moderating effect of KMP. A perusal of Figure 2 showing the CSFP increase relationship for each of the groups separately gives a better sense that the relationship is stronger (i.e. steeper slope) for the market focused group as compared to those of operation focused group.

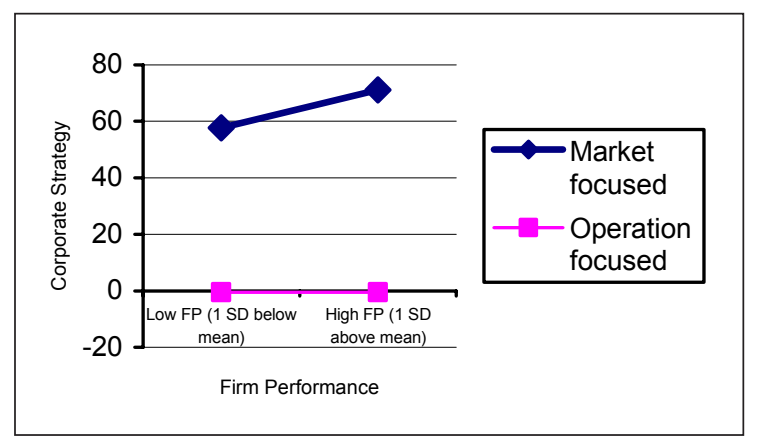

Fig. 2: Slopes for FP on CS for KMP (Market Focused and Operation Focused)

\section{CONTRIBUTION TO THE THEORY AND BODY OF KNOWLEDGE}

This study also appears to be the first of its kind within the context of the Malaysian perspective emphasising KMP in the strategy point of view and its contributions toward the development of the knowledge-based agenda of the country as well as within the organisational level. Thus, this study has theoretical implications for academicians and practitioners. The study combined aspects of disparate research and integrates a unique perspective and ideas from scholars in the field of strategic management (Porter, 1985; Stabell \& Fjeldstad, 1998); knowledge management (Darroch, 2003), information technology field (Tallon et al., 2000), and strategic marketing issues (Kohli \& Jaworski, 1990). This was done to illuminate the concept of KMP in an effort to develop a suitable KMP construct and framework. The framework on KMP has opened new avenues for research and scholastic discourse in knowledge management, information technology, and marketing and even in the strategic management fields. Secondly, the utilisation and integration of KMP in crafting CS from the viewpoint of strategy or the strategic management of 
knowledge and its operationalisation has yet to be looked into by research in the Malaysian view. Hence, the results of this finding empirically contribute to a new area in the Malaysian context since no previous research has been undertaken.

Thirdly, this study has made, a proposition for the structuring of KM concept, for example, KMP to be fully utilised in crafting the CS of the organisation because the results provided empirical evidence that KMP facilitates the success of a good business operation structure, which, in turn leads to better FP and contribute to a greater understanding of how KMP can improve FP, and some beneficial issues in a move toward knowledge-based development among industries in Malaysia.

The empirical result of relationships and differences on each of the choice of KMP and strategic response of CS reflected that KMP constitutes a base for making informed and intelligent resource allocation decisions. KMP which is concerned heavily on the knowledge-related activities appear to be one of the useful assets and can be utilised as strategic resources of the organisations as the study used empirical data in providing the explanation of the concept studies. Specifically, this study revealed that it may make more sense for firms to incorporate knowledge management practices in crafting their corporate strategies as a response to business needs since this study showed such traditional practice of crafting corporate strategy alone does not adequately enhance business activities in terms of firm performance objectives. This study appeared to contribute to a new understanding that KMP is not necessarily focused on the processes alone, instead its overall usage and utilisation toward crafting the CS as well as the orientation of the strategic response is crucial. Hence, the authority concerned on the agenda of the knowledge-based moves should ensure that organisations be wellequipped and utilise the KMP in crafting CS issues of the organisations as an initial move to direct the organisations toward the better planning and dealing the strategic and functional needs of the firm.

\section{IMPLICATIONS FOR PRACTICES TOWARD KNOWELDGE- BASED DEVELOPMENT}

These results and findings have noteworthy implications for both researchers and practitioners in the initial move toward the knowledge-based development of the country. Correspondingly, managers, practitioners, scholars, and organisations that attempt to incorporate KMP could take the following step to promote KMP in their organisations: 


\section{Managerial Contribution}

The management needs to encourage a culture of lifelong learning not only among the corporate level people involving top management, but also their corporate strategic personnel, because educators cannot teach everything that a student needs to know within a three or four-year programme. An environment that encourages self-learning must be inculcated where the personnel is facilitated in the transition toward performance of a highly knowledge-based organisation.

\section{Contribution to the Organisation}

The study verified the real benefits that practitioners and organisations experience with particular focus on private companies in Malaysia. It provides a straightforward answer for organisations in thinking about their most available resources: knowledge and human resource as well as on how to manage this efficiently and effectively through one proper system: knowledge management.

\section{Curriculum Development and Educators}

The impact of KMP in the perspective of crafting and even reorganisation of $\mathrm{CS}$ requires educators to design programme that promote lifelong learning. The increasing attention put by many in emphasising the need to have a KM system and practices in the organisational setting demands changes in the mindset of the educator to continually cope with the recent trends of corporate change in strategic management of the organisation. Co-operation between education and industry must be intensified so that knowledge advances in the value creation activities such as the need to systematise the process of identifying, acquiring, retaining, disseminating, utilising as well responding to knowledge issues within the strategic and functional needs of the organisation. Hence, this helps to create value and its effects on the performance of the firm can contribute to relevant curriculum development. The presence of the industry in the development of educational programmes can neiher be discounted, nor can the presence of the academician in the business organisations be considered trivial.

\section{CONCLUSION}

The results of this study add to our understanding of the relationship between CS and KMP and their significant implications toward the performance of the organisation and thus have the potential to contribute theoretically to 
both management strategy and knowledge management literature. The data suggested the presence of the concept of organisational fit between organisational structure and process. This finding is consistent with the earlier organisational literature. The presence of the organisational fit itself suggests that every organisation chooses its own target market and develops its own set of products and services. This domain decisions were supported by appropriate decisions concerning the organisation's technological, structure, and process.

The study revealed that KMP had a significant moderating effect on the relationship between the CS and FP. While previous studies claimed the CS can contribute to the performance of the organisation, this research indicated that organisation that adopts a specific type of strategy alone would sufficiently explain better FP although it significantly affects FP. All the three dimensions of the KMP; the KMP goal, the KMP support, and the KMP corporate valuechain have enabled the integration of the organisational, technological, and administrative issues to flow more effectively and efficiently. The presence of the value chain activities in organisations enable the process of acquiring, disseminating, and responding to the knowledge agenda and help organisations to pinpoint areas within the organisation where the KMP is creating value. Thus, this can serve as a model for an initial move among organisations to participate in the country's move toward the knowledge-based development agenda.

Nevertheless, having discussed the above conclusion, this study raised at least three limitations. Firstly, the response rate was high but the sample size (325) was relatively small. A larger sample would bring more statistical power. Secondly, the generalisability of the result may be limited since the majority of respondents was only those among the public-listed organisations listed in the Bursa Malaysia. The replication of this study in organisational contexts is necessary before the results can be generalized to the other form of organisations. Those in consideration may extend the study to the Multimedia Super Corridor (MSC) companies, the organisations registered with the Federation of Malaysia Manufacturers, the multinational companies in Malaysia, the government-linked companies and even those agencies and ministries under the Government of Malaysia. Thirdly, due to resource limitations, the research was cross-sectional, attempting to predict KMP in the aspect of CS of the organisation. In future research, this study should be extended to examine actual KMP using longitudinal data. This may provide more insights into KMP among organisations in Malaysia, as well as the relationship between additional issues in the corporate value-chain where KMP can add value not only to the organisations, but as main contributing factors toward the development of the knowledge-based issues and challenges in the country. 


\section{REFERENCES}

Aguinis, H. (2004). Complex MMR model. Regression analysis for categorical moderators (pp 32-33). New York: Guilford Press.

Asoh, D. A. (2004). Business and knowledge strategies: Alignment and performance impact analysis. Retrived January 2, 2005, from http:// proquest.umi.com.

Barney, J. B. (1991). Firm resources and strategic competitive advantage. Journal of Management, 17 (9), 49-61.

Barney, J. B. (1996). Gaining and assisting competitive advantage. AddisonWesly, Reading, MA.

Chandler, A.D., Jr. (1962). Strategy and structure: Chapters in the history of the industrial enterprise. Cambridge: MIT Press.

Cohen, J., \& Cohen, P. (1977). Statistical power analysis for the behavioural sciences (Rev. ed.). New York: Academic Press.

Conant, J.S., Mokwa, M.P., \& Varadarajan, P.R. (1990). Strategic types, distinctive marketing competencies and organisational performance: A multiple measures-based study. Strategic Management Journal, 11, 365-383.

Darroch, J. (2003). Developing a measure of knowledge management behaviors and practices. Retrieved from http:// proquest. umi. com.

Diakoulakis, I. E., Georgopoulos, N. B., Koulouriotis, D. E., \& Emiris, D. M. (2004). Towards a holistic knowledge management model. Journal of Knowledge Management, 8(1), 32-46.

Hair, J. F., Anderson, R. E., Tatham, R. L., \& Black, W. C. (1998). Multivariate data analysis (5th ed.). Upper Saddle River, NJ: Prentice Hall.

Hambrick, D. (1983). High profit strategies in mature industrial product business units. Academy of Management Journal, 3(2), 159-174.

Kohli, A., \& Jaworski. (1990, April). Market orientation: The construct, research propostions, and managerial implications. Journal of Marketing, 54, 1-18. 
Kogut, B., \& Zander, U. (1996). What do firms do? Co-ordination, identity and learning. Organisation Science, 7, 503-518.

Lengnick-Hall, M. L., \& Lengnick-Hall, C. A. (2003). Human resource management in the knowledge economy: New challenges, new roles, new capabilities. United States of America: Berrett-Koehler.

McCann, J. E., \& Buckner, M. (2004). Strategically integrating knowledge management initiatives. Journal of Knowledge Management, 8(1), 4763.

McGiven, M. H., \& Tvorik, D. (2005). Determinants of organisational performance. Retrieved from http://www.proquest.com.

Miles, R., \& Snow, C. C. (1978). Organisational strategy, structure and process. New York: McGraw-Hill.

Norziha, M.Z. (2005). The Impact of corporate strategy, corporate culture, core competence and human resource management practices on organisational performance. Unpublished doctoral dissertation, Graduate School of Management, Universiti Putra Malaysia, Malaysia.

Nunally, J. C. (1978). Psychometric theory. New York: McGraw-Hill.

Parnell, J. A., Lester, D. L., \& Menefee, M. L. (2000). Strategic as a response to organisational uncertainty: An alternative perspective on the strategy-performance relationship. Retrieved from http:// www. emerald-library.com.

Penrose, E. (1959). The theory of the growth of the firm. Oxford: Basil Blackwell, London. In Teece et al. (1997). Strategic Management Journal, 18(7), 509-533.

Porter, M. E. (1985). Competitive advantage: Creating and sustaining superior performance. New York: The Free Press.

Prahalad, C., \& Hamel, G. (1990). The core competence of the corporation. Harvard Business Review, 58 (3), 79-91.

Raja Hanaliza, R.A.T.(2005). The adoption of competitive advantage strategies among telecommunication firms. Unpublished doctoral dissertation Graduate School of Management, Universiti Putra Malaysia, Malaysia. 
Raja Suzana, R.K. (2005, July). Strategic linking of knowledge management practices and human resources management practice among MSC status organizations: Enhancing organization competitiveness. Paper presented at the International Conference on Knowledge Management. University Putra Malaysia, Putra World Trading Centre, Kuala Lumpur, Malaysia.

Raja Suzana. R.K. (2004). Knowledge management practices among MSC status organisations: A survey. Proceedings at the Fifth International Conference on Knowledge, Culture and Change in Organizations. University of Aegean, Rhodes, Greece. 19-22 July 2005.

Robbins, S. P. (1990). Organisation theory: Structure, design and application (3rd ed.) New Jersey: Prentice-Hall.

Rozhan O., Rahayu, \& Rashidah. (2001). Great expectation: CEO's perception of the performance gap of the HRM function in the Malaysian manufacturing sector Personnel Review, 30(1), 1\&2, 61-80.

Schendel, D. E. (1996). Editor's instruction of the 1996 Winter Special Issue: Knowledge and the firm. Strategic Management Journal, 17, 1-4.

Sekaran, U. (2000). Research methods for business. A skill building approach (5th ed.). New York: John Wiley.

Snyman, R., \& Kruger, C. J. (2004). The interdependency between strategic management and strategic knowledge management. Journal of Knowledge Management, 8(1), 5-19.

Stabell, C.B., \& Fjeldstad, O. D. (1998). Configuring value for competitive advantage: On chains, shops and networks. Strategic Management Journal, 19(5), 413-437.

Tallon, P.P., Kraemer, K.L., \& Gurbaxani, V. (2000). Executives' perceptions of the business value of information technology: A process-oriented approach. Journal of Management Information System, 16(4), 145-29.

Teece, D.J. (2000). Strategies for managing knowledge assets: The role of firm structure and industrial context. Long Range Planning, 33, 35-54.

Teece, D.M., Pisano, G., \& Shuen, A. (1999). Dynamic capabilities and strategic management. In M. H. Zack (Ed.), Knowledge and strategy (pp. 77-115). Boston: Butterworth, Heinemann. 
Wernerfelt, B. (1984) A resource-based view of the firm. Strategic Management Journal, 5(2), 171-180.

Zabid, A.R., \& Anatharaman, R.N. (1997, September). A study of corporate strategy and culture. Malaysian Management Review. 